\title{
RETINITIS OF PREGNANCY
}

\author{
BY
}

Lieut.-Col. Sir Jamshedji N. Duggan, Kt., C.I.E., O.B.E., D.O.(Oxon.)

AND

V. K. Chitnis, D.O.(Oxon. and Bom.), M.B., B.S.(Bom.), F.C.P.S.

Several cases of retinitis of pregnancy came under observation in the Sir C. J. Ophthalmic Hospital during the last three years, out of which three were found particularly interesting because of their widely differing eye-grounds, two having definitely benefited by termination of pregnancy while the third probably did so.

The first case was that of a young Mahommedan female, aged 25 years, 3rd para, first pregnancy having taken place twelve years ago. She came in for failing vision in both eyes. She was then in her seventh month of pregnancy. She had developed oedema of both legs and soon after vision began to fail and a fortnight later she visited the out-patient department of the Sir C. J. Ophthalmic Hospital. Vision had gone down in each eye to finger counting at 4 to 6 feet.

Fundus examination showed a well-developed neuro-retinitis, with copious exudate and oedema in the retinal tissues. Well-marked, soft-edged cotton-wool patches were prominent in the fundal picture. Both the maculae were oedematous and detachment of retina was present downwards and inwards in each eye. Both the eyes showed an identical fundal picture and seemed to have been affected with equal intensity. The onset appeared to be fairly sudden.

Urine was acid in reaction, specific gravity 1,020 , with 6 per cent. albumin and the deposit contained pus cells and hyaline casts.

The patient was advised elimination line of treatment and was immediately sent to the Bai Motlibai Obstetric Hospital for induction of labour. Labour was induced prematurely.

After induction of labour, the patient felt better. All the toxic symptoms disappeared. Fundal examination showed rapid disappearance of exudates and re-attachment of retina in each eye; when she returned to this Hospital a few days after induction of labour, her vision had improved to 6/18 in each eye and fundi had almost returned to normal.

The second case was that of a Mahommedan female, aged 35 years.

She was admitted to the Bai Motlibai Obstetric Hospital, when 
she was in her seventh month of pregnancy and had then developed signs of toxaemia, such as insomnia, headaches, pain in the praecordial region, fever and cough. Her blood pressure was $230 / 160 \mathrm{~mm}$. Urine was loaded with albumin, but there were hardly any casts or epithelial cells, although R.B.Cs. and pus cells were present. Labour was induced by laminaria tents. This was her fourth pregnancy. Her last child is $2 \frac{1}{2}$ years old, the previous two having died-the first at the age of five and the second when fifteen days old. All were full term babies. She was then transferred to the Petit Hospital for women for further treatment.

She was first sent to this Hospital for fundal examination, a week or ten days after labour was induced. The diagnosis then made was neuro-retinitis probably of renal origin. There was hardly any oedema of retinal tissues and the exudates were not of the cotton-wool type. She was sent again for fundal examination about three weeks later. She had then undergone an operation for sterilization. On both occasions, her vision could not be recorded as she was lying in bed and was not in fit condition to give correct replies. When she was examined on the second occasion the fundal picture was as follows:-

The right fundus showed all main arteries silver-wire; a partial star figure was present at the macula; veins were tortuous and of irregular calibre; secondary optic atrophy was showing its signs of approach ; dark-brown pigment patches were present, large in size, scattered but scarce, probably due to absorbing haemorrhages, as striation could be seen, usually met with in haemorrhages situated in the nerve-fibre layer. Left eye fundus showed an identical picture except for the macula which, instead of having a stellate exudate, had a few hard dots of white exudate irregularly aggregated around it.

After induction of labour, her blood pressure was found to be $168 / 116 \mathrm{~mm}$. Urine was not re-examined. But the symptoms of toxaemia had disappeared and vision showed considerable improvement.

Unfortunately, there was no opportunity afforded to see this case during the stage of toxaemia, before labour was induced. The first time she visited the Sir C. J. Ophthalmic Hospital was a few days after the termination of pregnancy.

This case did not show the true elements of retinitis usually seen in pregnancy toxaemias. History was obtainable that during the two previous pregnancies, she had noticed dimness of vision which had recovered after confinement. This may have been due to the slow onset of retinitis, the true nature of which could not be determined then. On the first examination, her fundi showed neuro-retinitis but there were no exudates of the cotton-wool type 
nor was there any oedema of the retinal tissues. No detachment of retina was present. It was thought then that the picture was complicated by cardio-vascular changes and high blood-pressure. The fundal picture seen at the second examination was probably the result of these two factors, together with the involvement of the kidneys. This case appeared to resemble that group of cases which begin primarily as chronic nephritis without having anything to do with pregnancy. Although the fundal picture differed from the usual type of retinitis seen in pregnancy cases, it was not impossible, however, to see cases of this type where sclerotic changes predominated in the fundus as a result of toxaemia.

However, the retinal lesions showed signs of early subsidence, after induction of labour. The haemorrhages had absorbed and had left dark-brown pigment patches; but what remained was the stellate exudate at the macula. The retinal vessels showed a very advanced degree of arterio-sclerotic changes. Prognosis is undoubtedly less grave in patients with retinitis who are not the subjects of antecedent chronic nephritis. It was difficult to decide this point in this case as the fundus showed elements of retinitis which closely resembled those seen in renal or arterio-sclerotic retinitis, although complicated by pregnancy.

The third case was seen in a young Mahommedan female, aged 24 years. It was peculiar in every respect. It was unilateral, only the right eye being affected. There was a well-marked opacity of the retina, suggestive of severe oedema of retinal tissues with large exudates having set in at the beginning. Some of the exudates still retained the soft-edged woolly characteristics. The disc appeared to be almost enveloped by them. No detachment of the retina was present and haemorrhages were not seen. Blood pressure was low, $90 / 65 \mathrm{~mm}$. Wassermann reaction was negative and urine showed no abnormality.

There was a history of two children having been delivered normally. But in the last pregnancy, which terminated accidentally at home, at the end of the seventh month, she had attacks of giddiness, vomiting and headaches which showed she had suffered from toxaemia. Blurring of vision occurred then, but no further details could be available from a totally ignorant woman of her type. Her parents were equally ignorant and were unable to throw any further light upon her symptoms. These observations are entirely based upon the clinical findings. It was not possible to ascertain if one eye or both eyes had developed visual disturbances. But one fact was certain, that vision had improved since the termination of pregnancy. As she still noticed difficulty in seeing with her right eye, she was brought to this Hospital for treatment, a month after pregnancy had terminated.

This case was suggestive of retinitis of pregnancy. The severe 
oedema of the retina was a point in favour. But why it should have affected one eye only, is a point difficult to understand. The other eye was normal or perhaps had returned to normal, as usually happens in such cases, after the termination of pregnancy. This eye had only traces of retinitis left in it, an occasional white streak along a blood-vessel or a few solitary areas of the retina which to a critical eye appeared more grey than the rest of the fundus. The disc appeared to be of normal hue.

All three cases occurred in Mahommedan women of young age. None of them had any ocular trouble during their first two pregnancies, which were full term and uneventful in every respect. Symptoms of toxaemia made their first appearance in the third pregnancy in the first and the third cases, while in the second they appeared in the fourth, although there was a vague history of some visual disturbance in the previous two pregnancies. In all three, ocular symptoms were noticed in the seventh month of pregnancy. In two, labour was induced prematurely, while in the third it came on accidentally. After the termination of pregnancy, not only did the symptoms of toxaemia subside but vision improved considerably and the retinitis showed signs of early subsidence. Wassermann reaction was negative in all the three cases. From every available clinical fact and previous record, there was no doubt that in the first case the retinitis was the direct outcome of the toxaemia of pregnancy, while in the third this relation was considered probable for want of definite evidence. In the second case, in all probability, the toxaemia had aggravated the retinitis which it was assumed to have existed already as a result of chronic nephritis. In all three, however, the ocular findings.differed widely from each other, each one having its own peculiarities. The question arises, from the study of these cases, whether it is common to meet with such widely differing types of retinitis in the toxaemias of pregnancy and whether each one of them can be attributed to the latter, or is there only one type of retinitis met with in pregnancy toxaemias and the other belongs to the antecedent chronic nephritis.

There are certain characteristics of retinitis of pregnancy which differ from the other forms of renal retinitis. They have been summed up by Semple, quoted by Foster Moore in his well-known book on medical ophthalmology. He says, "The sudden onset, the tremendous exudation into retina, the equally sudden cessation on removal of the cause if done promptly enough, the subsequent and complete restitution of visual acuity, all are in marked contrast to the usual course of retinitis of other forms of Bright's disease."

The retinal changes, Foster Moore observes, in these pregnancy cases are usually very severe, with copious exudate and oedema 
in the retinal tissues and detachment of the retina occurs from the pouring out of serum into the subretinal space, in a much larger proportion of them than in other forms of nephritis.

Other important features of this retinitis are that in those cases where chronic nephritis has not antedated the pregnancy, prognosis is less grave than in chronic nephritis in general.

The retinitis may become completely resolved and leave practically no ophthalmoscopic residue behind. Sight in these cases is often restored to normal and the patient may live for many years.

The retinitis does not as a rule recur in future pregnancies, where it has once been present and subsided. It most often develops after several pregnancies, though it may occur at the first.

With regard to the different groups of toxaemias of pregnancy, it is quite infrequent to meet with retinal lesions and optic nerve changes in the pernicious vomiting of pregnancy. Lesions of the retina and optic nerve are usually seen in other groups of toxaemia, such as $(a)$ the low reserve kidney, (b) pregnancy complicated by chronic nephritis, $(c)$ pre-eclamptic toxaemia, and $(d)$ eclampsia. The ocular findings in these different groups do not closely resemble each other. The retinitis of pregnancy, described by Semple, and characterised by sudden onset; retinal oedema and detachment of retina, is common in low reserve kidney, preeclampsia and eclampsia, while retinal haemorrhages and renal retinitis are usually seen in that group of toxaemias where chronic nephritis is complicating pregnancy. The eyegrounds, therefore, may form an important means of differentiating this kind of toxaemia from the rest, because retinal lesions differ so widely from each other in this and the other types of toxaemia. The importance of this differentiation lies in this fact, that very often the first manifestations of chronic nephritis appear to develop during the course of pregnancy, instead of before it, where recognition is frequently impossible until some weeks before delivery. Such a difficulty arises particularly in pre-eclampsia, where it is sometimes impossible to differentiate between it and severe chronic nephritis, when previous history is not known. It is here that ocular findings usually help to settle the diagnosis, as renal retinitis never occurs in pre-eclamptic toxaemia.

Apart from their value in differentiating various types of toxaemias, these changes in the eyegrounds which are primarily vascular in type are important from another point in that they serve a useful guide to estimate the degree of injury caused by the toxaemia to the vascular tree. In the beginning such lesions may be functional but later on if the toxaemia is allowed to progress may soon become organic or sclerotic. Appearance of softedged, cotton-wool patches and retinal haemorrhages always 
herald the onset of organic changes. Serious organic damage to the vascular system can be avoided, if at this stage pregnancy is terminated. On the other hand, if the toxaemia is allowed to continue until extensive retinitis has developed, permanent arteriolar sclerosis and persistent hypertension are practically inevitable.

From these considerations, it becomes obvious that of the three cases described, the first represents the characteristic type of retinitis of pregnancy described by Semple. This type alone offers a good prognosis; subsidence of retinal oedema, disappearance of exudates, reattachment of retina and complete restoration of vision, are the rule in these cases, provided pregnancy is interrupted immediately. It is difficult to explain why the retinal exudate and oedema persisted in the third case, even after the sudden interruption of pregnancy. It was not possible to determine the existence of similar retinal lesions in the other eye, in this case, previous to the delivery, but assuming that they had existed then and had disappeared after labour was over, it is quite inexplicable why they should have cleared in one eye, leaving the exudates and oedema unchanged in the other. It is not known if such a retinitis is ever unilateral. The urine did not show any abnormality and even the blood pressure was found to be low. This case was followed anxiously to see if the retinal lesions showed any signs of subsidence. but our eagerness ended in disappointment, as the patient ceased to visit the Hospital any more. It is therefore not possible to determine the exact nature of this case.

The second case had no points of similarity with the first except that after termination of pregnancy vision began to improve simultaneously with the subsidence of the toxaemia. But apart from the absorption of haemorrhages, the retinal lesions did not show any change for the better. There was a drop in the bloodpressure from its very high level, but it did not reach normal limits. From the foregoing considerations, it is not difficult to determine the nature of this case. The retinal lesions formed a picture which is usually seen in renal retinitis. It therefore becomes obvious from the nature of these lesions, together with the persistent high blood-pressure, that this case belongs to that group of toxaemia known as chronic nephritis complicating pregnancy. In this case it was not possible to determine the presence of chronic nephritis before pregnancy, nor is it possible to do so in all such cases. Difficulties in diagnosis of this toxaemia do not arise when pregnancy is known to have preceded by this condition, but when nothing is known about the case or symptoms of toxaemia are very mild in the beginning, diagnosis is not so easy. There are one or two points which are characteristic about this condition, besides albuminuria and high blood-pressure. Whenever disturbances of vision occur during the course of pregnancy com- 
plicated by chronic nephritis, they are invariably due to the presence of renal retinitis, and secondly, however variable the nature of the blood-pressure may be, the pressure does not fall to normal promptly after delivery, as in low reserve kidney, but usually remains high for months or even permanently. In other forms of toxaemia the retinal lesions show an early tendency towards disappearance and complete restoration of vision; such is not the case in this toxaemia. The retinitis persists and shows the typical characteristics of renal retinitis. This case undoubtedly exhibited these characters and left no doubt in the mind regarding the nature of toxaemia complicating the pregnancy.

A point which suggests itself from the study of this case is whether those cases in which arterio-sclerotic changes in the retinal vessels already exist in the early months of pregnancy, should be included into those groups of retinitis of pregnancy and whether such cases should be allowed to go to full term. Wagener believes that such cases should really belong to the group of cases having hypertension and chronic nephritis previous to pregnancy. In such cases, even if symptoms are mild in the beginning, exacerbations occur during the course of pregnancy and visual disturbances are usually due to the presence of renal retinitis. As regards the second question, Wagener holds that it should not be entirely decided upon the retinal changes, because they are more or less stationary, but in his opinion, a closer attention should be paid to the vascular damage done to the kidney and elsewhere; the latter may contraindicate the continuance of pregnancy even in the absence of an acute toxaemia.

Another point of interest concerns the ophthalmologist. Should he advise interruption of pregnancy, in the presence of commencing retinitis, in spite of the fact that complete subsidence of retinitis and restoration of vision usually occur in the end? Wagener is almost decisive on this point and warns the specialist not to be too cheerful about the very hopeful prognosis, as if he allowed the pregnancy to continue he may condemn the woman to become a chronic nephritic, whereas the prompt termination of the pregnancy may completely free her from this danger and the child also may have better chances of living.

\section{Summary}

Three cases of retinitis of pregnancy are described : the first case represents the characteristic form of retinitis; the second case belongs to the group of toxaemia of pregnancy complicated by chronic nephritis, and the third one exhibits features resembling the first one, yet its nature remains obscure :

(1) There is only one type of retinitis which can be called a retinitis of pregnancy, that described by Semple, characterised by 
sudden onset, oedema of retinal tissues, equally sudden cessation on removal of the cause and complete restoration of vision.

(2) Whenever chronic nephritis complicates pregnancy, the visual disturbances are due to renal retinitis.

(3) This retinitis is associated with high blood-pressure which, together with the signs of retinitis, have a tendency to persist after delivery.

(4) This form of retinitis forms a useful guide in differentiating chronic nephritis complicating pregnancy from pre-eclamptic toxaemia.

(5) It should really belong to the group of cases having hypertension and chronic nephritis preceding pregnancy.

(6) Apart from their differentiating value, lesions of the retina help us to estimate the damage done to the vascular tree.

(7) In the presence of commencing retinitis, the ophthalmologist should not hesitate to advise interruption of pregnancy.

\section{REFERENCES}

1. Foster Moore, R.- "Medical Ophthalmology." Second edition. pp. 175-176.

2. Williams, J. Whitridge.- "Obstetrics." Sixth edition, pp. 662, 635-651.

3. Wagener, Henry P.-Amer. Jl. of Ophthal., Vol. XVIII, pp. 263-264, 1935.

\section{THE RECOGNITION OF FLASHING COLOURED LIGHTS BY PERSONS WITH NORMAL AND DEFECTIVE COLOUR VISION}

BY

\section{H. V. Corbett and H. E. ROAF}

(FROM THE DEPARTMENT OF PHYSIOLOGY, THE UNIVERSITY OF LIVERPOOL)

Flashing lights and stationary lights viewed from a tossing vessel may be visible for only a short interval of time at each exposure, therefore it is important in testing colour vision to vary the duration of the exposure. Coloured lights are the forms of stimuli which occur in those trades in which colour recognition is important, for example, in railway, marine and air services; therefore the recognition of coloured lights is the most practical form of test. Recognition of coloured lights does not require training, whilst viewing objects through a telescope requires practice.

The Edridge-Green Lantern has apertures of different areas which when viewed at a constant distance of 20 feet represent fixed lights (e.g., a railway " bull's eye ") at different distances.

In 1912 a committee recommended a lantern for use by the Board of Trade. This lantern, in addition to a large single aperture, can be used with two small apertures, both of which may 